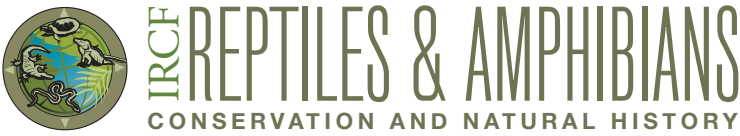

\section{Monitoring a Breeding Mugger (Crocodylus palustris) Population in the Girnar Wildlife Sanctuary near Junagadh, Gujarat, India}

\author{
Pranav Vaghashiya ${ }^{1}$, Devedra Chauhan ${ }^{2}$, and Raju Vyas ${ }^{3}$ \\ 193, Amrutam, Bapunagar Society, B/H Gaytri School, Joshipura, Junagadh, Gujarat, India (pranav4940@gmail.com) \\ ${ }^{2}$ Khodiyar Krupa, Asha Society, Shivnagar, Joshipura, Junagadh, Gujarat, India (drdevenchuhan@gmail.com) \\ ${ }^{3}$ Krishnadeep Tower, Mission Road, Fatehgunj, Vadodara, Gujarat, India (razoovyas@hotmail.com)
}

$\mathrm{T}$ he Mugger or Marsh Crocodile (Crocodylus palustris) is legally protected in India under Schedule I of the Indian Wildlife (Protection) Act, 1972 and is listed as vulnerable on the IUCN Red List (Choudhury and de Silva 2013). It is, however, frequently encountered and is one of the most adaptable crocodilian species in southern Asia (Da Silva and Lenin 2010). Largely as a consequence of legal protection and conservation measures by the State Forest Department and various NGOs, this species is commonly encountered and appears to be flourishing in myriad bodies of water throughout Gujarat state (Vyas 2018). Many habitats are now saturated with Muggers, and the increasing numbers are creating some serious intraspecific problems and also causing more frequent conflicts with humans (Vyas and Stevenson 2017). In particular, problems have been documented along the Vishwamitri River in Vadodara (Vyas and Bhatt 2004; Vyas and Bhavsar 2009; Vyas 2010, 2012, 2013, 2018) and the Narmada River in Bharuch (Vyas and Basu 2008).

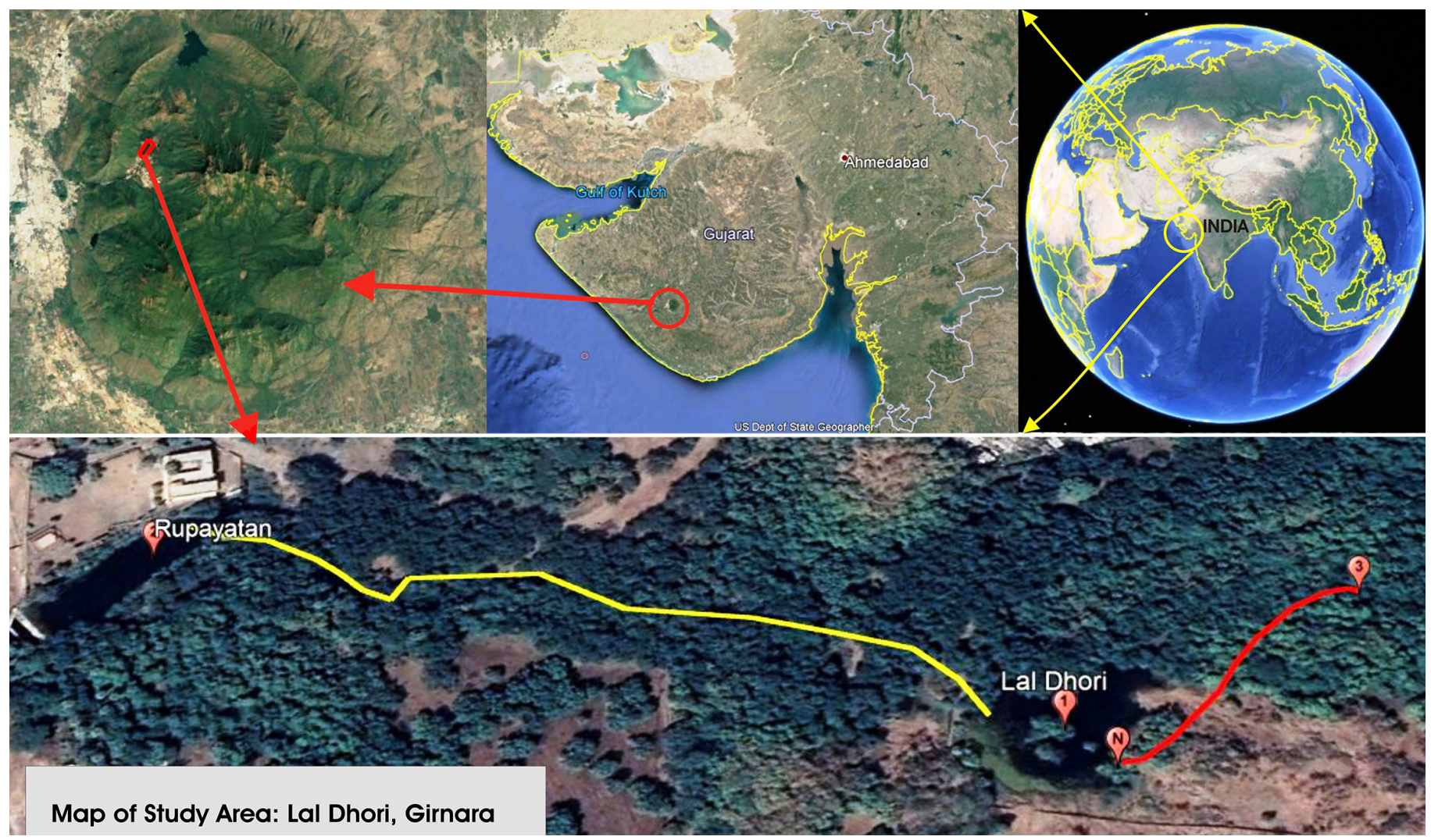

Fig. 1. Map of the study area in Gujarat, India, showing locations of Lal Dhori (1) and Rupayatan (2), the path of migration (yellow line), the nesting site $(\mathrm{N})$, the route along which hatchlings were transported (red line), and the site where hatchlings were transported to a pool of wet mud in the Girnar forest (3). 

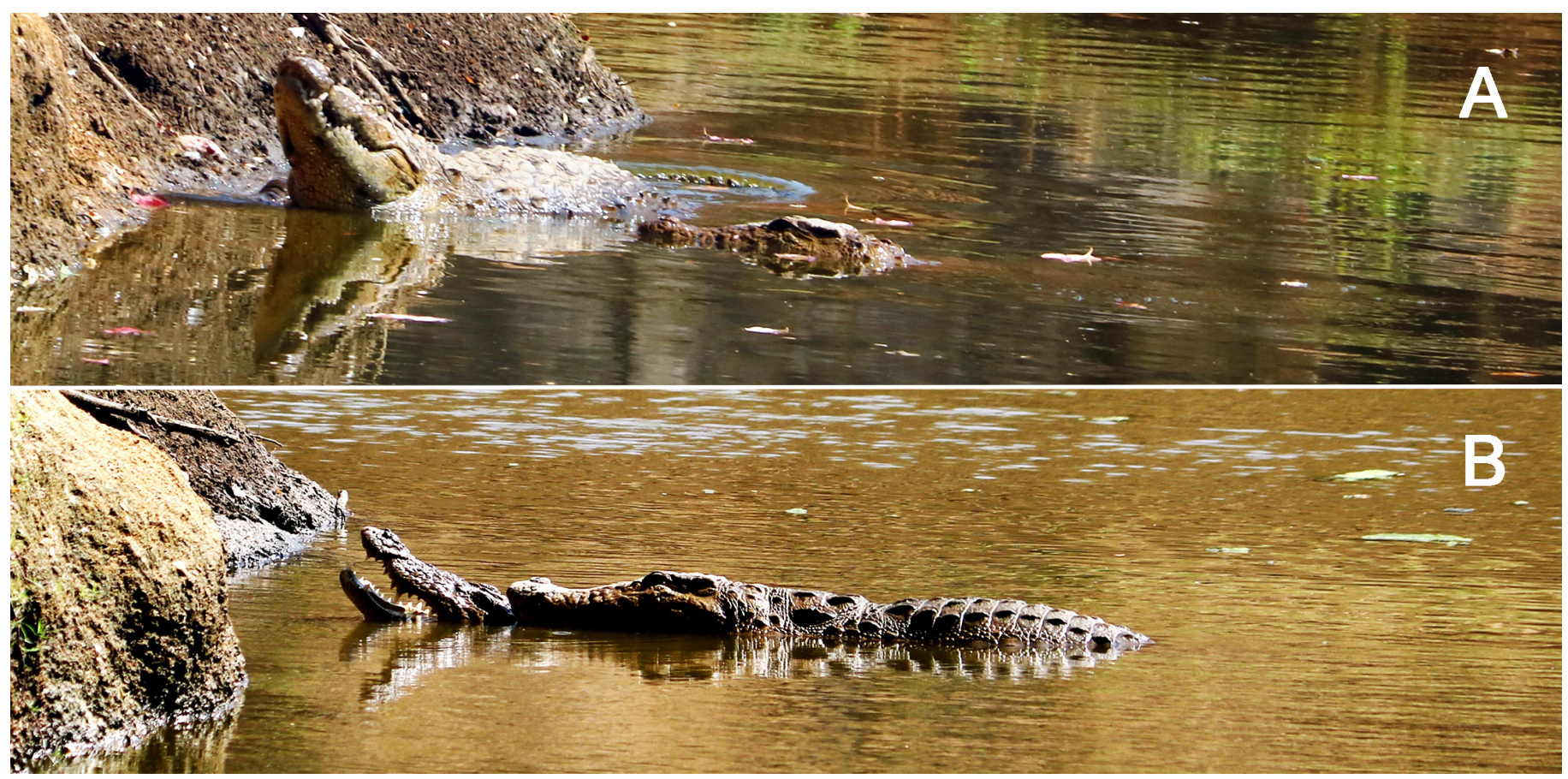

Fig. 2. Courtship behavior in Muggers (Crocodylus palustris): Male rubbing with his snout as he approaches the female from behind (A) prior to mounting her (B). Photographs by Pranav Vaghashiya.

\section{Methods}

From February through June 2019, we monitored a small population of Muggers in the vicinity of a small body of water called Lal Dhori $\left(21^{\circ} 32^{\prime} 17.87^{\prime \prime}\right.$, $70^{\circ} 30^{\prime} 9.79 " E ;$ Fig. 1), one of over a dozen small and large wetlands in and around the Girnar Hills near Junagadh, Gujarat State, India, with actively breeding Mugger populations (Vaghashiya et al. 2018). The Girnar Hills (100-1,100 m asl), the largest hill complex on

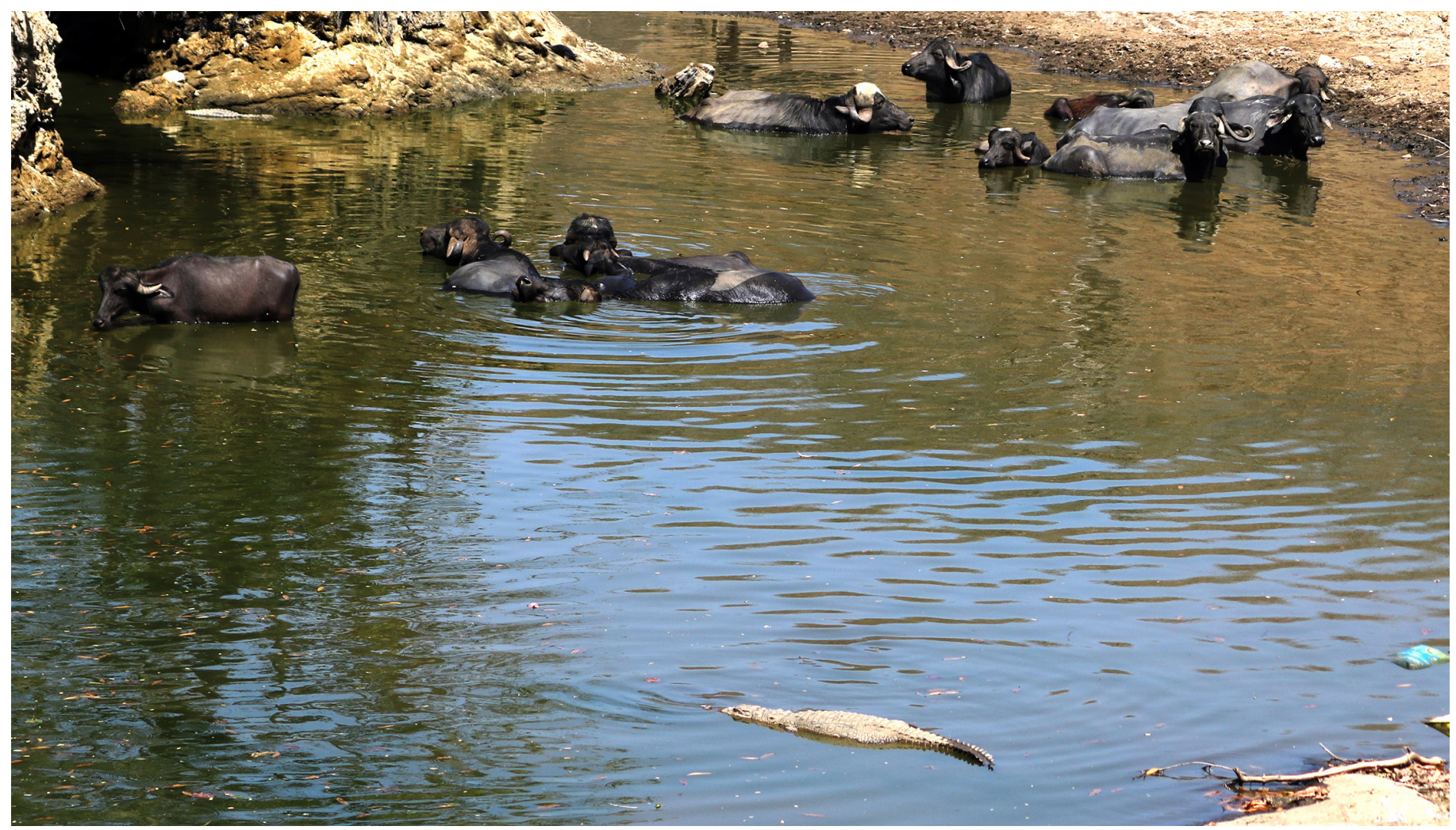

Fig. 3. The male and female Muggers (Crocodylus palustris) basking near opposite banks of the pond after mating. Photograph by Pranav Vaghashiya. 
the Saurashtra Peninsula, falls in the semiarid zone as defined by Champion and Seth (1968). Vegetation is characterized as dry mixed deciduous teak forest (Barqi 2000). As these forests provide one of the few remaining habitats of Asiatic Lions (Panthera leo persica), the entire region encompassing nearly $280 \mathrm{~km}^{2}$ is a wildlife sanctuary.

\section{Observations and Results}

On 15 February 2019, we observed two large Muggers (approx. $2-2.5 \mathrm{~m}$ in length) courting in shallow water by rubbing their bodies against each other, bubbling water, touching snouts, and the male circling the female until the male mounted the female (Fig. 2). During the entire sequence, which lasted about 30-40 min, the female grunted periodically with her mouth open (Fig. 2b). After mating, the male and female moved in opposite directions before basking on opposite sides of the pool (Fig. 3). We continued to observe this pair. During the first week of March, the female was swimming in a circular fashion around the entire pond with the male following her. She did not allow any further mating. During the second week of March, we did not see any further interactions between the duo, possibly because we were monitoring the animals during daylight only. On 19 March near dusk, we saw a few crocodiles leaving the wetland and migrating about $0.5 \mathrm{~km}$ downstream toward the Rupayatan Check-dam (2132'4.98”N, 70²9'59.59”E), movements probably attributable to declining water levels and food scarcity that typically correspond with the onset of summer at Lal Dhori.
During the late evening hours of 4 April 2019, we observed the female Mugger returning to Lal Dhori. Upon arrival, she began excavating a nest with her hindlimbs on the bank of the pool at Lal Dhori into which she laid eggs late that same night. After laying, she covered the nest with loose soil. A day later, the female and several resident Indian Flap-shelled Turtles (Lissemys punctata) were nowhere to be found; we suspected that they had migrated downstream to the Rupayatan Check-dam. By then, the entire pool at Lal Dhori had gone dry, leaving only a small puddle in what had been the center of the pond. After 62 days, on 5 June 2019, we observed a crocodile (probably the female) roaming near the nesting site. After spending 30-40 min near the nest, the crocodile disappeared into nearby thickets of riparian forest.

At about $0700 \mathrm{~h}$ on the morning of 13 June 2019 (70 days after oviposition), we observed the female Mugger returning to the nest site. She removed the topsoil from the nest and then transferred the hatchlings, one or two at a time, from the nest to a muddy area (Fig. 4) $178 \mathrm{~m}$ from the nest, transporting a total of 12 hatchlings and one infertile egg (Fig. 5). The last hatchling was transferred at $2024 \mathrm{~h}$ after almost twelve hours and five trips. That same night, light showers in the upper catchment areas of Lal Dhori led to a slight rise in water level. The next morning, we observed the female accompanied by her hatchlings swimming in the waters at Lal Dhori, having apparently transferred her hatchlings back downstream.

The following night, we counted only nine hatchlings in the pool, which the female closely monitored over the next few days in a small area of the pool near a burrow-like forma-

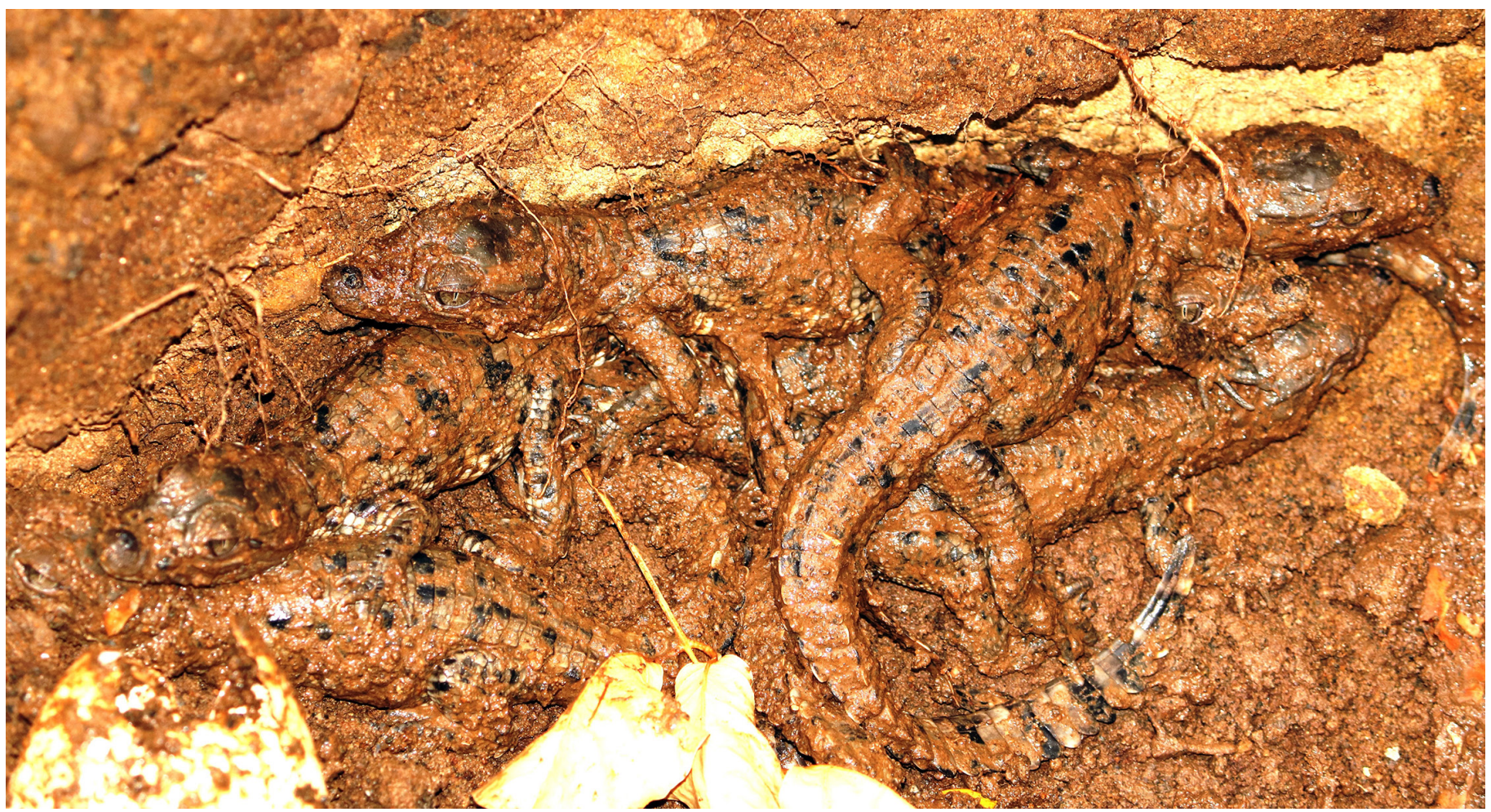

Fig. 4. Freshly hatched Muggers (Crocodylus palustris) in a pool of wet mud. Photograph by Pranav Vaghashiya. 

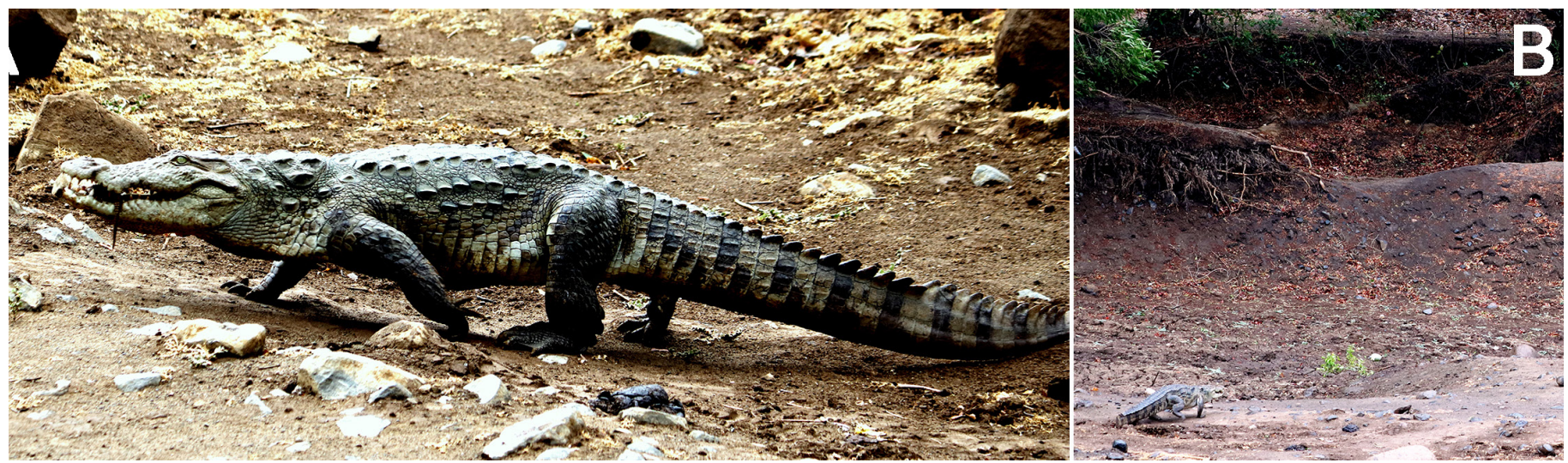

Fig. 5. A female Mugger (Crocodylus palustris) carrying a hatchling in her jaws (A) as she moves toward dense forest and a pool of wet mud (B). Photographs by Pranav Vaghashiya.

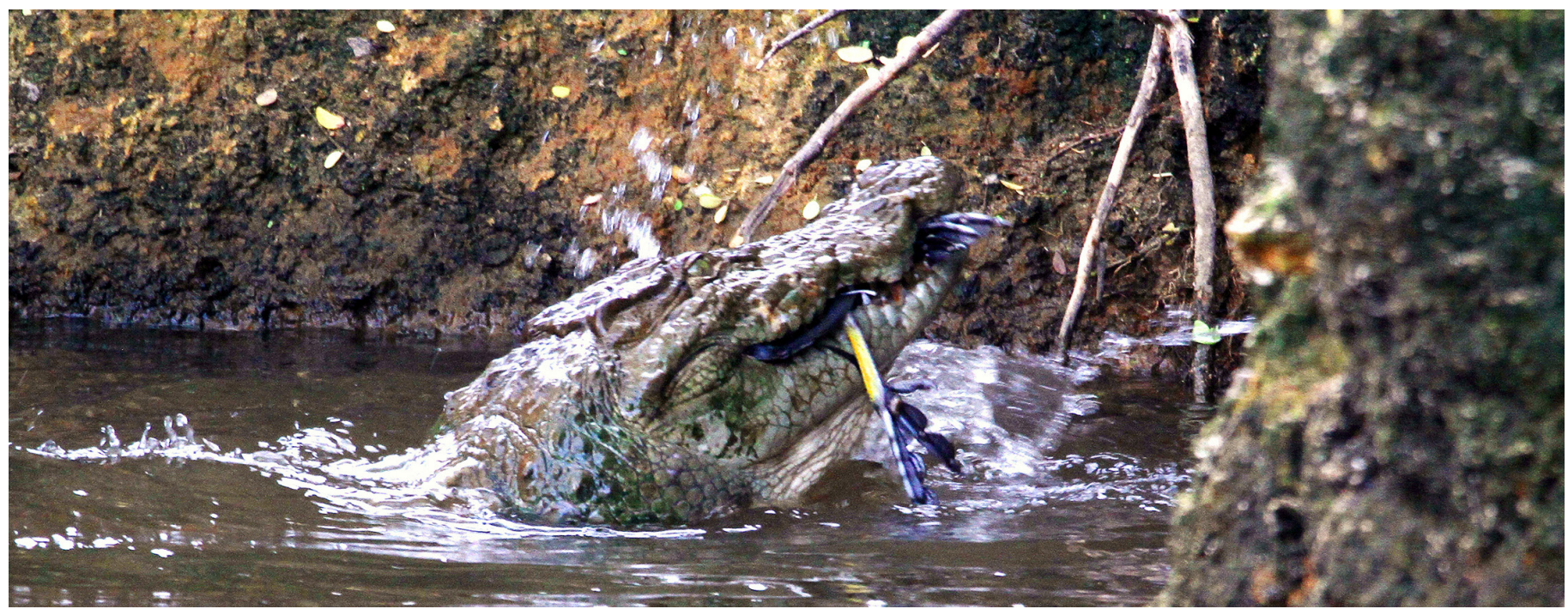

Fig. 6. A Mugger (Crocodylus palustris) preying on a Common Coot (Fulica atra). Photograph by Devendra Chauhan.

tion. After nine days, the hatchlings started foraging near the banks. We also observed five juveniles swimming in the pool; these had disappeared from the area about two months prior to this sighting. The female was aggressive toward the juveniles, presumably in an effort to protect her hatchlings.

On 22 June 2019, we observed an adult Mugger preying on a Common Coot (Fulica atra) (Fig. 6). One week later, we noticed the female Mugger being particularly aggressive toward one of the juveniles. After a continuous struggle that lasted about $30 \mathrm{~min}$, she caught hold of the juvenile (Fig. 7). Following this incident, we could not find a carcass or any remains of the juvenile, leading us to conclude that the juvenile was consumed in a clear case of cannibalism.

\section{Discussion}

Our observations of courtship, mating, and nesting coincide with the breeding season described in an earlier study by Whitaker and Whitaker (1984) in captivity. The courtship and mating behaviors also corresponded to those previously recorded by Dharmkumarsinhji (1947) and Whitaker and
Whitaker (1984). The latter recorded the incubation period lasting from 41 to 85 days, with much of the variation attributable to local environmental conditions. The 70-day incubation period we recorded coincides with the appropriate portion of the species' range.

Although 12 hatchlings were transported by the female to the forest, we observed only nine a day later. We cannot say whether the mother failed to retrieve all of the hatchlings or if they became prey of an unknown predator. Regardless, three missing hatchlings represent a 25\% loss. In 2017, Vaghashiya et al. (2018) reported a nest in the same wetland from which seven hatchlings emerged. Within two years, however, only four survived, a $43 \%$ loss (excluding one original survivor that disappeared on 29 June 2019).

That the female returned to the nest only to leave and return again a week later before excavating the hatchlings suggests that she was responding to vocalizations from the nest (e.g., Campbell 1973). Her subsequent transport of the hatchlings over a considerable distance to a larger upstream catchment, probably in search of a safer and moister site, 


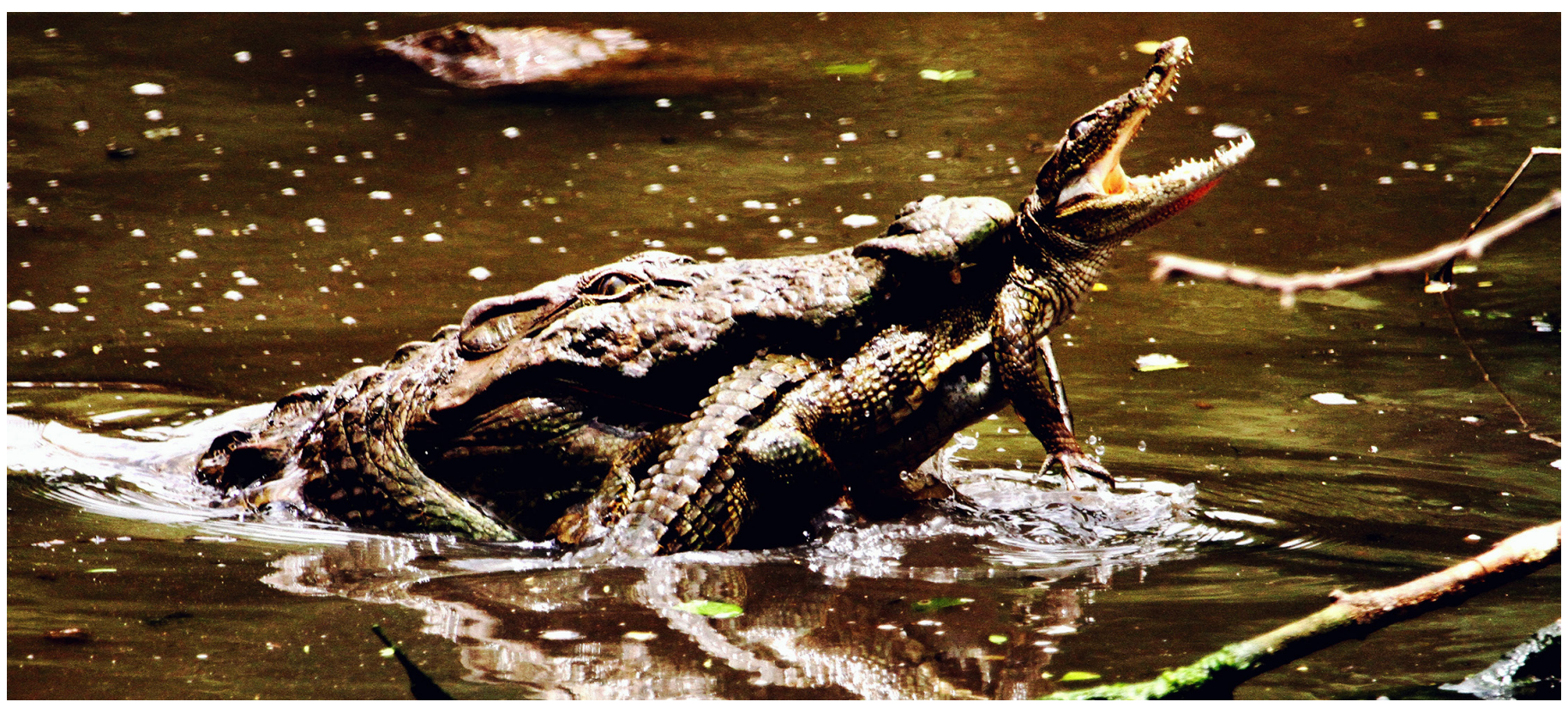

Fig. 7. The photographic evidence of cannibalism: An adult Mugger (Crocodylus palustris) cannibalizing a juvenile at the Lal Dhori wetland, Junagadh, Gujarat, India. Photograph by Devendra Chauhan.

would appear to emphasize the importance of moisture for the development of hatchlings. At Lal Dhori, the onset of monsoons usually occurs during the first week of June, but the rains were delayed by two weeks in this particular year. That delay might have prompted the female to transport the hatchlings to a more suitable upstream site.

Predation on birds, such as the Common Coot is not uncommon; Vyas (2012) recorded species of aquatic birds in the diet of Muggers. Female Muggers can be aggressive, especially when with hatchlings, but we do not know whether the attack we observed on the juvenile was motivated by maternal concern for her young or hunger. Cannibalism is not rare in crocodilians (e.g., Somaweera et al. 2013) and was recorded previously in a captive population of $C$. palustris (Reddy 1978). To the best of our knowledge, the incident described herein is the first report in nature.

\section{Acknowledgments}

We thank Amit Vaghashiya, Bhautik Dudhatra, Akhil Savliya, and Nihar Upadhay, members of Vasundhara Nature Club, Junagadh, for company and help with data collection. We also thank the staff of the Forest Department and Deputy Conservator of Forest, State Forest Department, Junagadh, Gujarat, for their support and help.

\section{Literature Cited}

Barqi, Q.H. 2000. Introduction, pp. 1-14. In: J.R.B. Alfred (ed.), Fauna of Gujarat (Part 1). Vertebrates. Zoological Survey of India, Calcutta, India.

Campbell, H.W. 1973. Observation on the acoustic behavior of crocodilians. Zoologica 58: 1-11.

Champion, H.G. and S.K. Seth. 1968. A Revised Survey of the Forest Types of India. Government of India, New Delhi, India.

Choudhury, B.C. and A. de Silva. 2013. Crocodylus palustris. The IUCN Red List of Threatened Species 2013: e.T5667A3046723. <http://doi.org/10.2305/ IUCN. UK.20132.RLTS.T5667A3046723.en>.

Da Silva, A. and J. Lenin. 2010. Mugger Crocodile Crocodylus palustris, pp. 94-98. In: S.C. Manolis and C. Stevenson (eds.), Crocodiles. Status Survey and Conservation Action Plan. Third Edition. Crocodile Specialist Group, Darwin, Northern Territory, Australia.

Dharmkumarsinhji, K.S. 1947. Mating and the parental instinct of the marsh crocodile (Crocodylus palustris, Lesson). Journal of the Bombay Natural History Society 47: 174 .

Reddy, P.S. 1978. Crocodile breeding in Indira Gandhi Zoological Park. Wildlife Club Newsletter (Dehra Dun) 6: 68-69.

Somaweera, R., M. Brien, and R. Shine. 2013. The role of predation in shaping crocodilian natural history. Herpetological Monographs 27: 23-51.

Vaghashiya, P.M., B. Dudhatra, and R. Vyas. 2018. Parental behaviour of mugger (Crocodylus palustris) at Lal dhori, Junagadh, Gujarat, India. Crocodile Specialist Group Newsletter 37(2): 16-18.

Vyas, R. 2010. Mugger (Crocodylus palustris) population in and around Vadodara City, Gujarat State, India. Russian Journal of Herpetology 17: 43-50.

Vyas, R. 2012. Current status of Marsh Crocodiles Crocodylus palustris (Reptilia: Crocodylidae) in Vishwamitri River, Vadodara City, Gujarat, India. Journal of Threatened Taxa 4: 3333-3341.

Vyas, R. 2013. Recent scenario of mugger (Crocodylus plustris) population in three districts of Gujarat State, India, pp. 220-226. In: Proceeding of the World Crocodile Conference. 22 nd Working Meeting of the IUCN-SSC Crocodile Specialist Group. IUCN, Gland, Switzerland.

Vyas, R. 2018. Result of the 2015 Mugger Crocodile (Crocodylus palustris) count at Vadodara, Gujarat, India. Reptiles e Amphibians 25: 20-25.

Vyas, R. and S. Bhatt. 2004. The mugger (Crocodylus palustris) population, problems, panic and rescue operation in and around Vadodara City. Crocodile Specialist Group Newsletter 23(3): 6-9.

Vyas, R. and D. Basu. 2008. Controversial dam site now mugger conflict site. Crocodile Specialist Group Newsletter 27(2): 28-30.

Vyas, R. and S.R. Bhavsar. 2009. Movement of an individual mugger into urban areas of Vadodara City, Gujarat State, India. Crocodile Specialist Group Newsletter 28(3): 5-7.

Vyas, R. and C. Stevenson. 2017. Review and analysis of human and Mugger Crocodile conflict in Gujarat, India from 1960 to 2013. Journal of Threatened Taxa 9: 11016-11024.

Whitaker, R. and Z. Whitaker. 1984. Reproductive biology of mugger (Crocodylus palustris). Journal of the Bombay Natural History Society 81: 297-317. 